\title{
Relative validation of the adapted Mediterranean Diet Score for Adolescents by comparison with nutritional biomarkers and nutrient and food intakes: the Healthy Lifestyle in Europe by Nutrition in Adolescence (HELENA) study
}

Raquel Aparicio-Ugarriza ${ }^{1,2}$, Magdalena Cuenca-García ${ }^{3,4}$, Marcela Gonzalez-Gross 1,5 , Cristina Julián ${ }^{6}$, Silvia Bel-Serrat7, Luis A Moreno ${ }^{5,6}$, Christina Breidenassel ${ }^{1,8}$, Mathilde Kersting ${ }^{9}$, Aline B Arouca ${ }^{10}$, Nathalie Michels ${ }^{10}$, Theodora Mouratidou ${ }^{6}$, Yannis Manios $^{11}$, Jean Dallongeville ${ }^{12}$, Frédéric Gottrand ${ }^{13}$, Kurt Widhalm ${ }^{14}$, Anthony Kafatos ${ }^{15}$, Denes Molnár ${ }^{16}$, Stefaan De Henauw 10, 17, Marc J Gunter ${ }^{2}$ and Inge Huybrechts ${ }^{2, *}$ on behalf of the HELENA Consortium

'ImFINE Research Group, Department of Health and Human Performance, Facultad de Ciencias de la Actividad Física y del Deporte (INEF), Universidad Politécnica de Madrid, Madrid, Spain: ${ }^{2}$ nternational Agency for Research on Cancer (IARC), 150 cours Albert Thomas, 69372 Lyon Cedex 08, France: ${ }^{3}$ Department of Medical Physiology, School of Medicine, Granada University, Granada, Spain: ${ }^{4}$ Department of Physical Education, School of Education, University of Cadiz, Puerto Real, Spain: ${ }^{5}$ Centro de Investigación Biomédica en Red de Fisiopatología de la Obesidad y Nutrición (CIBERObn), Instituto de Salud Carlos III, Madrid, Spain: ${ }^{6}$ GENUD (Growth, Exercise, Nutrition and Development) Research Group. Faculty of Health Sciences (FCS). Instituto Agroalimentario de Aragón (IA2). Instituto de Investigación Sanitaria Aragón (IIS Aragón), University of Zaragoza, Spain: ${ }^{7}$ National Nutrition Surveillance Centre, School of Public Health, Physiotherapy and Sports Science, University College Dublin, Dublin, Republic of Ireland: ${ }^{8}$ Institut für Ernährungs- und LebensmittelwissenschaftenHumanernährung, Rheinische Friedrich-Wilhelms Universität, Bonn, Germany: ${ }^{9}$ Research Institute of Child Nutrition Dortmund, Dortmund, Germany: ${ }^{10}$ Department of Public Health, Ghent University, Ghent, Belgium: " $D$ Department of Nutrition and Dietetics, School of Health Sciences and Education, Harokopio University, Athens, Greece: ${ }^{12}$ Inserm U744, Institut Pasteur de Lille, Université Lille Nord de France, Lille, France: ${ }^{13}$ Université Lille, Inserm U995, CHU Lille, France: ${ }^{14}$ Division of Clinical Nutrition and Prevention, Department of Pediatrics, Medical University of Vienna, Vienna, Austria: ${ }^{15}$ Preventive Medicine and Nutrition Clinic, University of Crete, Heraklion, Crete, Greece: ${ }^{16}$ Department of Pediatrics, University of Pécs, Pécs, Hungary: ${ }^{17}$ Department of Health Sciences, Vesalius, Hogeschool Gent, Ghent, Belgium

Submitted 25 October 2017: Final revision received 30 January 2019: Accepted 25 February 2019

\begin{abstract}
Objective: To investigate whether adherence to the adapted Mediterranean Diet Score for Adolescents (MDS_A) and the adapted Mediterranean Diet Quality Index for Adolescents (KIDMED_A) is associated with better food/nutrient intakes and nutritional biomarkers.

Design: The Healthy Lifestyle in Europe by Nutrition in Adolescence (HELENA) study is a cross-sectional study aiming to obtain comparable data on a variety of nutritional and health-related parameters in European adolescents aged $12 \cdot 5-17.5$ years.

Setting: Nine European countries.

Participants: European adolescents ( $n$ 2330) recruited to the HELENA study. Dietary intake was obtained with $24 \mathrm{~h}$ dietary recalls, an FFQ and a Food Choices and Preferences questionnaire. MDS_A was calculated as a categorical variable using cut-offs (MDS_A), as a continuous variable (zMDS_A) and with energy adjustments (zEnMDS_A). The KIDMED_A score was also calculated. Results: Multilevel linear regression analysis showed positive associations for zMDS_A and KIDMED_A with serum levels of vitamin D, vitamin C, plasma folate, holo-transcobalamin, $\beta$-carotene and $n-3$ fatty acids, while negative associations were observed with trans-fatty acid serum levels. For categorical indices, blood biomarkers showed few significant results. zMDS_A and KIDMED_A showed
\end{abstract}


positive associations with vegetables and fruits intake, and negative associations with energy-dense and low-nutritious foods. zMDS_A and KIDMED_A were positively associated with all macronutrients, vitamins and minerals (all $P<0 \cdot 0001$ ), except with monosaccharides and PUFA for KIDMED_A and cholesterol for both indices $(P<0.05)$.

Conclusions: ZMDS_A and KIDMED_A have shown the strongest associations with the dietary indicators and biomarkers that have been associated with the Mediterranean diet before, and are therefore considered the most appropriate and valid Mediterranean diet scores for European adolescents.

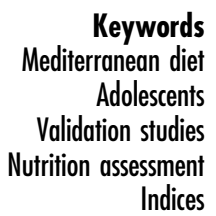

The Mediterranean diet is considered one of the healthiest dietary models, and potential health benefits of its adoption during childhood and adolescence have been suggested ${ }^{(1-3)}$. Higher adherence to the Mediterranean diet may reduce the negative effect of overweight and obesity and decrease different chronic non-communicable diseases such as $\mathrm{CVD}^{(1)}$. Likewise, greater adherence to the Mediterranean diet could reduce the burden of malnutrition (overnutrition and micronutrient deficiency) ${ }^{(4)}$.

Valid dietary indices adapted for children and adolescents are needed to assess the adherence to dietary guidelines among this young population group. Throughout the past decades, numerous diet quality indices or scores measuring adherence to the Mediterranean dietary guidelines have been developed $^{(5)}$, especially for adults. Mediterranean dietary scores specifically designed for children and adolescents have been applied based on specific recommendations for these age groups, such as the Mediterranean Diet Quality Index for children and adolescents (KIDMED) ${ }^{(6)}$ and several revised versions of the original Mediterranean Diet Score (MDS), among others ${ }^{(7-13)}$. Nevertheless, there are few studies investigating the use and validity of these indices in a European adolescent population ${ }^{(14)}$. The cross-sectional Healthy Lifestyle in Europe by Nutrition in Adolescence (HELENA) study provides data about nutrient and food intakes and nutritional biomarkers ${ }^{(15)}$ which could be used to compare and validate dietary indices for adolescents using an evidence-based approach.

Therefore, the aim of the present study was to investigate whether adherence to the adapted Mediterranean Diet Score for Adolescents (MDS_A) and the adapted KIDMED for Adolescents (KIDMED_A) is associated with better food and nutrient intakes as well as nutritional biomarker serum profiles in European adolescents. Different variants of these two scores have been examined, considering the guidelines from the original score, although also considering specific dietary needs (e.g. calcium and vitamin $\mathrm{D}$ for attaining peak bone mass) and restrictions (e.g. alcohol not recommended) for this young population group.

\section{Methods and materials}

\section{Study design}

The HELENA study is a population-based multi-centre investigation of the nutritional and lifestyle status among
European adolescents. Data were collected from October 2006 to December 2007 and fieldwork took place in ten European cities of nine countries: Vienna (Austria), Ghent (Belgium), Lille (France), Dortmund (Germany), Athens (Greece), Heraklion (Greece), Pécs (Hungary), Rome (Italy), Zaragoza (Spain) and Stockholm (Sweden). The purpose of the study was to obtain standardized, reliable and comparable data from a random sample of European adolescents on a broad battery of relevant nutrition and health-related parameters. This included dietary intake, food choices and preferences, blood indicators of lipid metabolism and glucose metabolism, vitamin and mineral status, anthropometry, physical activity, fitness and genetic markers. The entire description of the HELENA study design and sampling procedure has been published previously ${ }^{(16,17)}$.

\section{Participants}

The study population included 3528 adolescents $(52.3 \%$ females) aged $12 \cdot 5-17 \cdot 5$ years. Adolescents were excluded from the database a posteriori if they met one or more of the following exclusion criteria: age $<12.5$ or $\geq 17.5$ years; no measurement of weight and/or height; completion of $<75 \%$ of the tests; participating simultaneously in another clinical trial; or contracting an acute infection during the week prior to the examination ${ }^{(16)}$. As a result of logistical problems (limited staff capacity for collecting and analysing $24 \mathrm{~h}$ dietary recall data), there was no nutrient intake information from Heraklion or Pècs participants, for which case they were excluded.

For one purpose of the present study, we analysed the association between the adapted MDS and food and nutrient intakes without exclusion of under-reporters, resulting in 2330 adolescents (53.8\% females), and with exclusion of under-reporters, resulting in 1804 adolescents (52.6\% females). Under-reporting was considered when the individual ratio of energy intake divided by the estimated BMR was lower than $0 \cdot 96^{(18)}$. The group of underreporters consisted of a higher percentage of females $(57.8 \% v$. $52.6 \%$ plausible reports; $P=0.036)$ and had higher median (minimum, maximum) BMI values $(22.5$ $(15 \cdot 0,45 \cdot 6) \mathrm{kg} / \mathrm{m}^{2} v \cdot 20 \cdot 1(14 \cdot 1,40 \cdot 8) \mathrm{kg} / \mathrm{m}^{2}$ in the plausible reports; $P<0 \cdot 001)$.

Additionally, to investigate the relationship between different indices and nutritional biomarkers, blood samples 
were collected in a randomly selected sub-sample of the total HELENA study population (1089 adolescents) of whom 697 had two 24 h dietary recalls. Following the same criteria, we analysed with exclusion of under-reporters resulting in 552 adolescents (52.3\% females).

For the second aim of the present study, we examined the association between the adapted KIDMED and food and nutrient intakes. For this index, under-reporters were not excluded as the adapted KIDMED index was partly based on the dietary questionnaire data and not only on $24 \mathrm{~h}$ recall data. The power for the adapted KIDMED score was already reduced since several individuals were excluded because they did not complete the FFQ or the Food Choices and Preferences (FCP) questionnaire. The total sub-sample for this index was 1114 adolescents (56.5\% females). To analyse the association between adapted KIDMED and nutritional biomarkers, 552 adolescents were included ( $52.3 \%$ females).

The study was conducted following the ethical guidelines of the Declaration of Helsinki, the Good Clinical Practice rules, and the legislation about clinical research in human subjects in each of the participating countries. Written informed consent was obtained from all adolescents, their parents or guardians, and the protocol was approved by the Human Research Review Committees of the centres involved ${ }^{(17)}$.

\section{Dietary intake assessment}

Dietary intake was obtained by means of $24 \mathrm{~h}$ dietary recalls $^{(19)}$, an FFQ and the FCP questionnaire ${ }^{(20,21)}$. The $24 \mathrm{~h}$ dietary recalls were collected via the HELENA-DIAT (Dietary Assessment Tool) software on two nonconsecutive days within a period of 2 weeks. Adolescents completed the $24 \mathrm{~h}$ dietary recall autonomously in the computer classroom during school time and dietary intake was referred to the day before the interview; therefore, no information on Fridays and Saturdays was available.

This tool was adapted from a previous version developed and validated for Flemish adolescents ${ }^{(22)}$. This assessment tool is based on six meal occasions (breakfast, morning snacks, lunch, afternoon snacks, evening meal, evening snacks) referring to the previous day. Trained dietitians assisted the adolescents to complete the $24 \mathrm{~h}$ dietary recalls when needed. Adolescents autonomously selected all the consumed foods and beverages from a standardized food list in the HELENA-DIAT ${ }^{(23)}$. Items not available in the list could be added by the participant at any moment. Foods were translated to nutrients by use of the German Food Code and Nutrient Data Base (Bundeslebensmittelschlüssel (BLS) Version II.3.1) ${ }^{(24,25)}$. The Multiple Source Method was used to estimate the usual dietary intakes of nutrients and foods ${ }^{(26,27)}$. This statistical modelling technique takes account of within-person and between-person variability and calculates usual intakes corrected for age, sex and study centre.
The FFQ was designed to estimate adolescents' habitual food intake ${ }^{(28)}$ and was based on the Health Behaviour in School-aged Children (HBSC) FFQ, which was validated in a Belgian youth population ${ }^{(29)}$. In the current study, three questions have been selected from the FFQ: fruits, vegetables and sweets. There were seven answer categories ranging from 'never' up to 'more than once a day'. The answer 'never' was taken to count as 0 points and 'once a day, every day' and 'more than once a day' were merged together and categorized as 1 point.

The FCP questionnaire aimed to explore attitudes and issues of concern among adolescents regarding food choices, preferences, healthy eating and lifestyle ${ }^{(20,21)}$. From this questionnaire, 'usually skipping breakfast' was collected with five answer categories ranging from 'strongly disagree' up to 'strongly agree'. When participants answered 'moderately agree' or 'strongly agree', the score was 1 point. Additionally, 'How often do you consume fast food?' ranging from 'never' up to 'each day' was considered in the index score. The score was 1 point if participants answered from 'often' up to 'each day'.

\section{Adapted Mediterranean diet score for adolescents}

Adherence to the Mediterranean dietary pattern was assessed by an adapted version of the traditional MDS developed for adults as reported by Trichopoulou et al. ${ }^{(30)}$. The traditional MDS for adults includes nine components (vegetables; fruits and nuts; legumes; cereals; fish; monounsaturated fat:saturated fat ratio; dairy products; meat and poultry; and wine); each component (except for alcohol intake) is assigned a score of 0 or 1 using the sex-specific medians as cut-off values (below and above, respectively). Dairy products and meat (including poultry), as detrimental components, are reversely scored. In addition, 1 point is given for alcohol intake within a specified range: $5-25 \mathrm{~g} / \mathrm{d}$ for women and $10-50 \mathrm{~g} / \mathrm{d}$ for men; intakes above score as ' 0 '.

In our proposal, we modified the MDS for use in 12.517.5-year-old adolescents (MDS_A). We used age- and sexspecific median intakes of the study participants as a cut-off value for each component. Alcohol intake was scored as a detrimental component since ethanol consumption is not recommended for children and adolescents, while dairy products were scored as a beneficial component because dairy is recommended in growing age, namely childhood and adolescence ${ }^{(6)}$. However, an MDS variant including dairy products as a detrimental component had also been calculated and validated ${ }^{(30)}$. As such, four different versions of the adapted adolescent MDS were created as categorical variables (see Table 1 for more details):

1. MDS_A_7P_2N, with seven positive components (fruits, vegetables, pulses, cereals, fish and seafood, monounsaturated fat:saturated fat ratio and dairy products) and two negative components (meat and alcohol); 
Table 1 Overview of the components of the adapted MDS and the adapted KIDMED for adolescents*

\begin{tabular}{|c|c|c|c|}
\hline \multicolumn{2}{|r|}{ Components } & Criteria for scoring & Score \\
\hline $\begin{array}{l}\text { Adapted Mediterranean Diet Score for } \\
\text { Adolescents by Z-score method (zMDS_A) }\end{array}$ & $\begin{array}{l}\text { 1. Fruits (excluding juices) nuts, seeds and olives } \\
\text { 2. Vegetables (excluding potatoes) } \\
\text { 3. Fish and seafood } \\
\text { 4. Legumes (excluding fresh peas, sweet corn } \\
\text { and broad beans) } \\
\text { 5. Cereals: bread and rolls, flour, cereals, rice } \\
\text { and other cereals, pasta, potatoes } \\
\text { 6. Monounsaturated fat:saturated fat ratio } \\
\text { 7. Dairy products: white milk, buttermilk, yoghurt, } \\
\text { fromage blanc and cheese. } \\
\text { 8. Meat (including poultry) } \\
\text { 9. Alcohol }\end{array}$ & $\begin{array}{l}\text { Mediterranean diet } Z \text {-scores of nine components, including } \\
\text { seven positive and two negative (meat and alcohol) }\end{array}$ & $\begin{array}{l}\text { The sum of the values } \\
\text { from the positive } \\
\text { components and } \\
\text { deducting the negative } \\
\text { components, with a } \\
\text { higher score indicating } \\
\text { higher adherence to } \\
\text { Mediterranean diet }\end{array}$ \\
\hline $\begin{array}{l}\text { Adapted Mediterranean Diet Quality Index } \\
\text { for children and adolescents (KIDMED_A) }\end{array}$ & $\begin{aligned} & \text { 1. } \text { Fruits } \\
& \text { 2. Vegetables } \\
& \text { 3. Fish and seafood } \\
& \text { 4. Fast food } \\
& \text { 5. Pulses (bean, lentils, chickpea, peas, broad } \\
& \text { beans) } \\
& \text { 6. Pasta, rice and potatoes } \\
& \text { 7. Cereals or grains for breakfast } \\
& \text { 8. Nuts } \\
& \text { 9. Olive oil } \\
& \text { 10. Breakfast } \\
& \text { 11. Dairy products: yoghurt, cheese and curd } \\
& \text { 12. Confectionery products for breakfast: baked } \\
& \text { 13. Soods or pastries } \\
& \text { 13. Sweets and candies }\end{aligned}$ & $\begin{array}{l}\text { Takes a piece of fruit or fruit juice every day }=+1 \\
\text { Has a second fruit every day }=+1 \\
\text { Has fresh or cooked vegetables regularly once/d }=+1 \\
\text { Has fresh or cooked vegetables more than once/d }=+1 \\
\text { Consumes fish regularly (at least } 2-3 \text { times/week })=+1 \\
\text { Goes to a fast-food (hamburger) restaurant more than } \\
\text { once/week }=-1 \\
\text { Likes pulses and eats them more than once/week }=+1 \\
\text { Consumes pasta or rice almost every day } \\
\quad(\geq 5 \text { times/week) }=+1 \\
\text { Has cereals or grains (bread, etc.) for breakfast }=+1 \\
\text { Consumes nuts regularly (at least } 2-3 \text { times } / \text { week })=+1 \\
\text { Uses olive oil at home }=+1 \\
\text { Skips breakfast }=-1 \\
\text { Has a dairy product for breakfast (yoghurt, milk, etc.) }=+1 \\
\text { Has commercially baked goods or pastries for breakfast }=-1 \\
\text { Takes two yoghurts and/or some cheese }(40 \mathrm{~g} \text { ) daily }=+1 \\
\text { Takes sweets and candy several times every day }=-1\end{array}$ & $\begin{array}{l}\text { Questions denoting a } \\
\text { negative connotation } \\
\text { with respect to the } \\
\text { Mediterranean diet } \\
\text { were assigned a value } \\
\text { of }-1 \text {, and those with a } \\
\text { positive aspect, }+1 \\
\text { (see criteria for } \\
\text { scoring). The sums of } \\
\text { the values (only if the } \\
\text { criteria for scoring are } \\
\text { met) from the } \\
\text { administered test and } \\
\text { the index range from } \\
-4 \text { to } 12, \text { with a higher } \\
\text { score indicating higher } \\
\text { adherence to } \\
\text { Mediterranean diet }\end{array}$ \\
\hline $\begin{array}{l}\text { Adapted Mediterranean Diet Score for } \\
\text { Adolescents (MDS_A) }\end{array}$ & $\begin{array}{l}\text { 1. Vegetables (excluding potatoes) } \\
\text { 2. Legumes (excluding fresh peas, sweet corn } \\
\text { and broad beans) } \\
\text { 3. Fruits (excluding juices) and nuts, seeds and } \\
\text { olives } \\
\text { 4. Cereals: bread and rolls, flour, cereals, rice } \\
\text { and other cereals, pasta, potatoes } \\
\text { 5. Fish and seafood } \\
\text { 6. Monounsaturated fat:saturated fat ratio } \\
\text { 7. Dairy products: white milk, buttermilk, yoghurt, } \\
\text { fromage blanc and cheese. } \\
\text { 8. Meat (including poultry) } \\
\text { 9. Alcohol }\end{array}$ & $\begin{array}{l}\text { Sex- and age- specific median intakes were used as cut-offs } \\
\text { except for alcohol intake (given the age range of the } \\
\text { adolescents, alcohol intake recommendation was set at } 0 \mathrm{~g} \text { ). } \\
\text { For components considered to be healthy (vegetables, } \\
\text { legumes, fruit and nuts, cereals, fish, monounsaturated fat: } \\
\text { saturated fat ratio and dairy products), intakes above the } \\
\text { median score } 1 \text { and intakes below the median score } 0 \text {. Meat } \\
\text { and alcohol components were scored in the reverse as } \\
\text { components presumed to be detrimental. Intakes above the } \\
\text { median score } 0 \text { and intakes below the median score } 1\end{array}$ & $\begin{array}{l}\text { The sum of the values } \\
\text { from the positive } \\
\text { components and } \\
\text { deducting the negative } \\
\text { components, with a } \\
\text { higher score indicating } \\
\text { higher adherence to } \\
\text { Mediterranean diet }\end{array}$ \\
\hline
\end{tabular}




\section{Neselic Health Nutrition}

Table 1 Continued

\section{Components}

Adapted Mediterranean Diet Score for Adolescents excluding alcohol (MDS_A_NA)

Adapted Mediterranean Diet Score for Adolescents 8 components (MDS_A_NA_6P_2N)

Adapted Mediterranean Diet Score for Adolescents 9 components

MDS_A_6P_3N

Adapted Mediterranean Diet Score for Adolescents excluding alcohol by Z-score method (zMDS_A_NA) olives olives olives

9. Alcohol
1. Vegetables (excluding potatoes)

2. Legumes (excluding fresh peas, sweet corn and broad beans)

3. Fruits (excluding juices) and nuts, seeds and

4. Cereals: bread and rolls, flour, cereals, rice and other cereals, pasta, potatoes

5. Fish and seafood

6. Monounsaturated fat:saturated fat ratio

7. Dairy products: white milk, buttermilk, yoghurt, fromage blanc and cheese

8. Meat (including poultry)

1. Vegetables (excluding potatoes)

2. Legumes (excluding fresh peas, sweet corn and broad beans)

3. Fruits (excluding juices) and nuts, seeds and

4. Cereals: bread and rolls, flour, cereals, rice and other cereals, pasta, potatoes

5. Fish and seafood

6. Monounsaturated fat:saturated fat ratio

7. Dairy products: white milk, buttermilk, yoghurt, fromage blanc and cheese

8. Meat (including poultry)

1. Vegetables (excluding potatoes)

2. Legumes (excluding fresh peas, sweet corn and broad beans)

3. Fruits (excluding juices) and nuts, seeds and

4. Cereals: bread and rolls, flour, cereals, rice and other cereals, pasta, potatoes

5. Fish and seafood

5.

7. Dairy products: white milk, buttermilk, yoghurt, fromage blanc and cheese

8. Meat (including poultry)

1. Vegetables (excluding potatoes)

2. Legumes (excluding fresh peas, sweet corn and broad beans)

3. Fruits (excluding juices) and nuts, seeds and olives

4. Cereals: bread and rolls, flour, cereals, rice and other cereals, pasta, potatoes

5. Fish and seafood

6. Monounsaturated fat:saturated fat ratio

7. Dairy products: white milk, buttermilk, yoghurt, fromage blanc and cheese

8. Meat (including poultry)
Criteria for scoring

Score

Sex- and age- specific median intakes were used as cut-offs. The sum of the values For components considered to be healthy (vegetables, legumes, fruit and nuts, cereals, fish, monounsaturated fat: saturated fat ratio and dairy products), intakes above the median score 1 and intakes below the median score 0 .

Meat component was scored in the reverse as a component presumed to be detrimental. Intakes above the median score 0 and intakes below the median score 1

from the positive components and deducting the negative components, with a higher score indicating higher adherence to Mediterranean diet

Sex- and age- specific median intakes were used as cut-offs. The sum of the values For components considered to be healthy (vegetables, legumes, fruit and nuts, cereals, fish, monounsaturated fat: saturated fat ratio), intakes above the median score 1 and intakes below the median score 0 . Meat and dairy products components were scored in the reverse as components presumed to be detrimental. Intakes above the median score 0 and intakes below the median score 1 components and components, with a higher score indicating higher score indicating Mediterranean diet

Sex- and age- specific median intakes were used as cut-offs except for alcohol intake (given the age range of the adolescents, alcohol intake recommendation was set at $0 \mathrm{~g}$ ). For components considered to be healthy (vegetables, legumes, fruit and nuts, cereals, fish and monounsaturated fat:saturated fat ratio), intakes above the median score 1 and intakes below the median score 0 . Meat, alcohol and dairy products components were scored in the reverse as components presumed to be detrimental. Intakes above the median score 0 and intakes below the median score 1

Mediterranean diet $Z$-scores of eight components, including seven positive and one negative (meat)

The sum of the values from the positive components and deducting the negative components, with a higher score indicating higher adherence to Mediterranean diet
The sum of the values from the positive deducting the negative components, with a higher score indicating higher adherence to Mediterranean diet 


\section{Public Health Nutrition}

Table 1 Continued

Score

Adapted Mediterranean Diet Score for Adolescents by Z-score method, energy adjusted (zEnMDS A)

Adapted Mediterranean Diet Score for Adolescents by $Z$-score method, energy adjusted (zEnMDS A NA)

Adapted Mediterranean Diet Quality Index for children and adolescents excluding pulses and potatoes (KDMED_A NP)
1. Vegetables (excluding potatoes)

Legumes (excluding fresh peas, sweet corn and broad beans)

3. Fruits (excluding juices) and nuts, seeds and olives

4. Cereals: bread and rolls, flour, cereals, rice and other cereals, pasta, potatoes

5. Fish and seafood

6. Monounsaturated fat:saturated fat ratio

7. Dairy products: white milk, buttermilk, yoghurt, fromage blanc and cheese

8. Meat (including poultry)

9. Alcohol

1. Vegetables (excluding potatoes)

. Legumes (excluding fresh peas, sweet corn and broad beans)

3. Fruits (excluding juices) and nuts, seeds and olives

4. Cereals: bread and rolls, flour, cereals, rice and other cereals, pasta, potatoes

5. Fish and seafood

6. Monounsaturated fat:saturated fat ratio

7. Dairy products: white milk, buttermilk, yoghurt, fromage blanc and cheese

8. Meat (including poultry)

1. Fruits

2. Vegetables

3. Fish and seafood

4. Fast food

6. Cereals or grains for breakfast

7. Nuts

8. Olive oil

9. Breakfast

10. Dairy products: yoghurt, cheese and curd

11. Confectionery products for breakfast: baked goods or pastries

12. Sweets and candies
Mediterranean diet $Z$-scores of nine components including, seven positive and two negative (meat and alcohol). Each food item should be divided by total energy intake

Mediterranean diet $Z$-scores of eight components, including seven positive and one negative (meat). Each food item should be divided by total energy intake

Takes a fruit or fruit juice every day $=+1$

Has a second fruit every day $=+1$

Has fresh or cooked vegetables regularly once/d $=+1$

Has fresh or cooked vegetables more than once/d $=+1$

Consumes fish regularly (at least 2-3 times/week) $=+1$

Goes to a fast-food (hamburger) restaurant more than

once/week $=-1$

Consumes pasta or rice almost every day

$(\geq 5$ times/week $)=+1$

Has cereals or grains (bread, etc.) for breakfast $=+1$

Consumes nuts regularly (at least $2-3$ times/week) $=+1$

Uses olive oil at home $=+1$

Skips breakfast $=-1$

Has a dairy product for breakfast (yoghurt, milk, etc.) $=+1$ Has commercially baked goods or pastries for breakfast $=-1$

Takes two yoghurts and/or some cheese $(40 \mathrm{~g})$ daily $=+1$

Takes sweets and candy several times every day -1 of the values components and deducting the negative components, with a higher score indicating higher adherence to Mediterranean diet

The sum of the values components and deducting the negative components, with a higher score indicating higher adherence to Mediterranean diet

Questions denoting a negative connotation with respect to the Mediterranean diet were assigned a value of -1 , and those with a positive aspect, +1 (see criteria for scoring). The sums of the values (only if the criteria for scoring are met) from the

administered test and -4 to 11 , with a higher score indicating higher adherence to Mediterranean die 
2. MDS_A_NA_7P_1N, with seven positive components (fruits, vegetables, pulses, cereals, fish and seafood, monounsaturated fat:saturated fat ratio and dairy products) and one negative component (meat), excluding alcohol ('NA' stands for 'no alcohol');

3. MDS_A_NA_6P_2N, with six positive components (fruits, vegetables, pulses, cereals, fish and seafood, and monounsaturated fat:saturated fat ratio) and two negative components (dairy and meat), excluding alcohol; and

4. MDS_A_6P_3N, with six positive components (fruits, vegetables, pulses, cereals, fish and seafood, monounsaturated fat:saturated fat ratio) and three negative components (dairy, meat and alcohol).

MDS_A_7P_2N and MDS_A_NA_7P_1N are directly based upon the original MDS for adults, considering alcohol as a negative component for adolescents in MDS_A_7P_2N and ignoring the alcohol component for this young population in MDS_A_NA_7P_1N. To ease the readability throughout the paper, two standard MDS_A scores that are closest to the original MDS have been abbreviated as MDS_A and MDS_A_NA, respectively.

MDS_A and MDS_A_NA were also calculated as continuous variables using standardized $Z$-scores (in which each component was included as a $Z$-score rather than a binary variable): without energy adjustment, zMDS_A and zMDS_A_NA; and with energy adjustment, zEnMDS_A and ZEnMDS_A_NA. All indices were also analysed excluding under-reporters. Higher scores indicate higher adherence to the Mediterranean diet. More details of the components and cut-offs used to calculate the adapted zMDS_A are shown in Table 1.

\section{Adapted KIDMED for adolescents}

A second index to assess the adherence to the Mediterranean diet in our European adolescents was developed based on the KIDMED score, an index developed for children and adolescents proposed by Serra-Majem et al. ${ }^{(6)}$.

The original KIDMED ${ }^{(6)}$ is calculated based upon a test that includes sixteen questions which could be selfadministered or conducted by interview (paediatrician, dietitian, etc.). The index ranged from -4 to 12 , where questions denoting a negative connotation were assigned a value of -1 and those with a positive connotation, a value of +1 .

In our adapted version, we used data from repeated $24 \mathrm{~h}$ dietary recalls, the FFQ and the FCP questionnaire. Information on the consumption of pulses, cereals or grains for breakfast, yoghurts and cheese, baked goods or pastries, dairy products, olive oil and nuts were taken from the $24 \mathrm{~h}$ recalls. Potatoes, pasta and rice were also obtained from the $24 \mathrm{~h}$ dietary recalls. Questions about the usual consumption of fruits, vegetables and sweets were obtained by means of the FFQ. Furthermore, questions related to fast food and breakfast skipping were taken from the FCP questionnaire. The KIDMED_A as a categorical variable ranged from -4 to 12 , with a higher score 
indicating higher adherence to the Mediterranean diet. Furthermore, two variants of KIDMED_A were calculated as categorical variables (see Table 1 for more details):

1. KIDMED_A_NP, not including pulses and potatoes; and

2. KIDMED_A_NPH, not including pulses, potatoes and fast food (e.g. hamburger).

The components and the criteria for scoring the KIDMED_A are presented in Table 1.

Results pertaining to zMDS_A and KIDMED_A are provided in Tables 2-7 in the present paper. However, the detailed results for all other indices (MDS_A_7P_2N, MDS_A_7P_1N, MDS_A_NA_6P_3N, zMDS_A_NA, zEnMDS_A, zEnMDS_A_NA, KIDMED_A_NPH and KIDMED_A_NP) are presented in the online supplementary material, Supplemental Annexes 1, 2 and 3.

\section{Biochemical analyses}

Fasted blood samples were collected by venepuncture at school between 08.00 and 10.00 hours according to a standardized blood collection protocol. Details about the sampling, processing and transportation have been published elsewhere $^{(31)}$. For the current analyses, nutritional biomarkers and biomarkers with an important role in nutritional metabolism have been selected as objective indicators.

Plasma 25-hydroxyvitamin D was analysed by ELISA using a kit (OCTEIA 25-Hydroxy Vitamin D) from Immunodiagnostic Systems (Frankfurt, Germany) and measured with a Sunrise ${ }^{\mathrm{TM}}$ Photometer by TECAN (Hamburg, Germany). The sensitivity of this method is $5 \mathrm{nmol} / \mathrm{l}$ for 25-hydroxyvitamin D and the variation is below $6 \%$. Although plasma vitamin D concentrations are influenced by numerous factors such as sunlight exposure and adiposity, evidence indicated moderate correlations with dietary intake ${ }^{(32)}$. Vitamin $\mathrm{C}$ was analysed in plasma by reversed-phase HPLC (Sykam, Gilching, Germany) using UV detection (UV-VIS 205; Merck, Darmstadt, Germany). The CV of vitamin C was $4.4 \%$. Strong correlations of dietary intake of vitamin $\mathrm{C}$ with serum ascorbic acid concentrations have been shown mainly when habitual dietary intakes of vitamin $\mathrm{C}$ are relatively modest ${ }^{(33,34)}$.

Plasma folate $(\mathrm{CV}=5.4 \%)$ and total homocysteine ( $\mathrm{CV}=10.7 \%$ ) were determined by means of an immunoassay using the Immunolite 2000 analyser (DPC Biermann $\mathrm{GmbH}$, Bad Nauheim, Germany) and holo-transcobalamin $(\mathrm{CV}=5 \cdot 1 \%)$ was measured by an automated microparticle enzyme immunoassay with the AxSYM analyser (Abbott Laboratories, Abbott Park, IL, USA). Folate intakes correlate weakly with serum/plasma concentrations since many factors can influence the bioavailability of dietary folate and, therefore, serum/plasma folate concentrations ${ }^{(32)}$.

Retinol, $\alpha$-tocopherol and $\beta$-carotene were analysed in plasma using reversed-phase HPLC (Sykam) using UV detection (UV-VIS 205; Merck). The variation of the method is below $3 \%$ for all the vitamins. Plasma retinol concentrations are responsive to vitamin A intake only in individuals with inadequate vitamin A status ${ }^{(35)}$. Also, there are moderate correlations between blood concentrations of carotenoids and fruit and vegetable intakes ${ }^{(34-36)}$.

Serum phospholipid fatty acid composition (CV $=<4.4 \%$ ) was measured by capillary GC (model 3900; Varian GmbH, Darmstadt, Germany) after extraction performed by thin-layer chromatography. Serum TAG were determined enzymatically on the Dimension RxL clinical chemistry system (Dade Behring, Schwalbach, Germany) using the manufacturer's reagents and instructions. There is moderate correlation between $n$ - 3 fatty acid intake and plasma phospholipid levels although reflecting intake in the short to medium term ${ }^{(37,38)}$. Good correlations have been shown between the intake of specific types of trans-fatty acid and their levels in blood; however, the correlation between the total sum of trans-fatty acid intake and the sum of serum trans-fatty acid levels is only weak ${ }^{(39,40)}$. Likewise, plasma TAG has been found to be positively correlated with total fat intake and negatively with fibre intake. Levels may to some extent be indicative of the level of dietary fibre intake, but the findings to date are contradictory ${ }^{(34,41)}$.

\section{Statistical analysis}

Statistical analyses were performed using the statistical software package IBM SPSS Statistics for Windows version 21.

Pearson $\chi^{2}$ and $t$ tests were used to test for differences between sexes in categorical and continuous variables, respectively. Normality was evaluated visually and based on the skewness of the data distributions. Skewness of variables on intake ranged from 0.869 (meat intake) to 9.809 (alcohol intake; due to a high number of non-consumers). Since these variables were studied in a large sample, it was considered that parametric tests were allowed without transformations. However, variables with a skewness $>3$ were transformed (logarithmic transformation and square-root transformation were tested) and the multilevel analyses were repeated with the transformed data. A log-transformation of holo-transcobalamin was also performed in the present study.

Multilevel linear regression analysis with inclusion of a random intercept for study centre was used to examine the relationship of the different Mediterranean diet indices - MDS_A (see online supplementary material, Supplemental Annexes 1, 2 and 3), MDS_A_NA (Supplemental Annexes 1, 2 and 3), zMDS_A (Tables 2, 4 and 6), zMDS_A_NA (Supplemental Annexes 1, 2 and 3), zEnMDS_A (Supplemental Annexes 1, 2 and 3), zEnMDS_ A_NA (Supplemental Annexes 1, 2 and 3) and KIDMED_A (Tables 3, 5 and 7), which were calculated with and without exclusion of the under-reporters except for KIDMED_A that was calculated only for the full population - with foods, nutrient intakes and blood biomarkers.

Multilevel linear regression analysis was also performed between MDS_A_NA_6P_2N, MDS_A_6P_3N, 
Table 2 Association between the adapted Mediterranean Diet Score for Adolescents by Z-score method (zMDS_A) and food intakes among adolescents aged 12.5-17.5 years from nine European countries, Healthy Lifestyle in Europe by Nutrition in Adolescence (HELENA) study

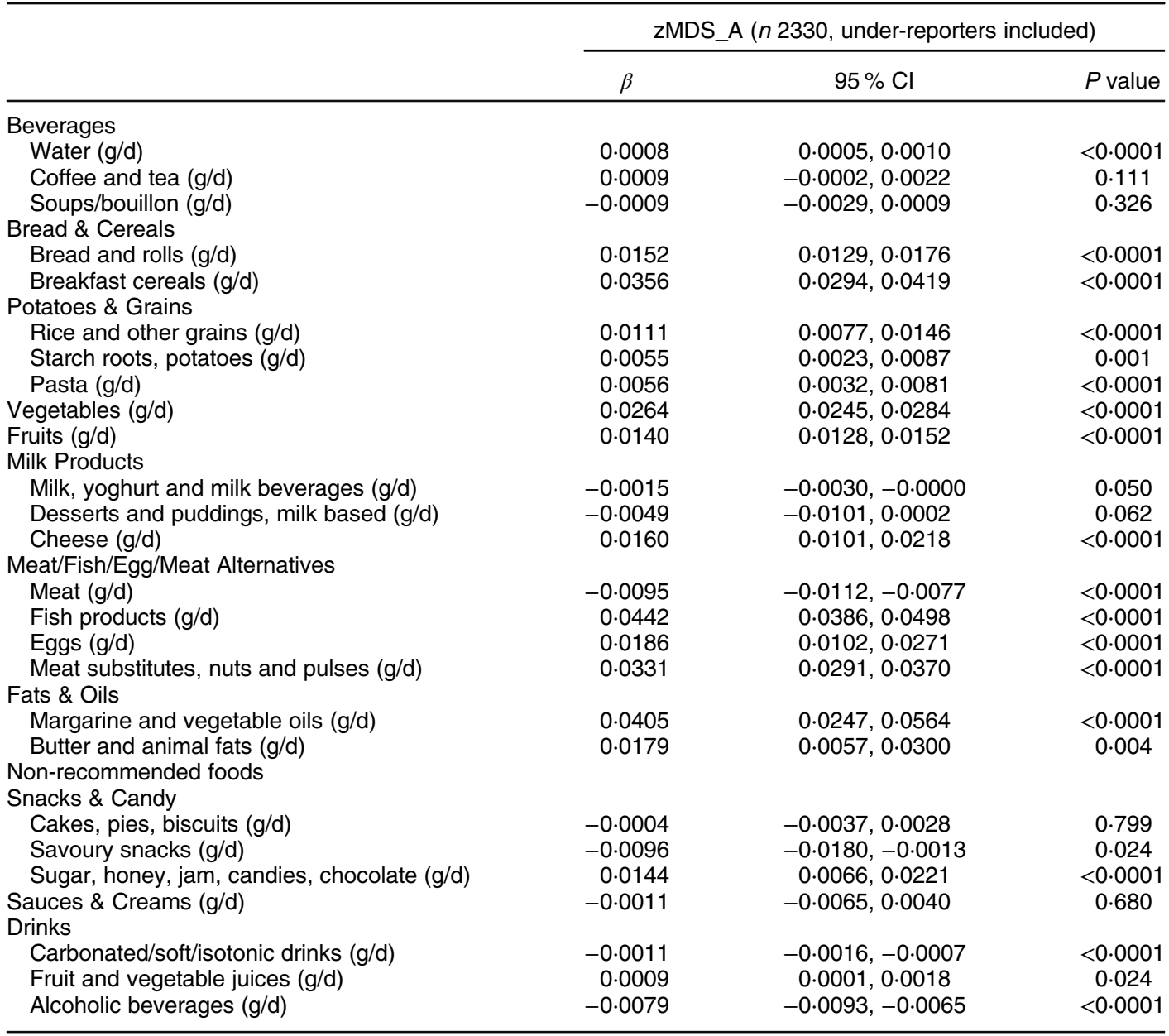

$\beta$, standardized regression coefficient.

Multilevel regression analyses with inclusion of a random intercept for centre and corrected for age and sex as independent variables. Bonferroni correction resulted in level of significance $<0.0019$.

KIDMED_A_NPH and KIDMED_A_NP (Supplemental Annex 3) and nutritional biomarker status. Confounders (age and sex) were entered as covariates. The level of statistical significance was controlled for multiple testing and a Bonferroni correction was applied to lower the significance level $(\alpha)$ account of the number of tests (foods $=0.05 /$ number of tests; nutrients $=0.05 /$ number of tests; biomarkers $=0 \cdot 05 /$ number of tests) to control family-wise error rate. Therefore, statistical significance was considered with $P$ values of $0.0019,0.0013$ and 0.005 for the association between all indices and foods, nutrients and biomarkers, respectively.

\section{Results}

For all adapted MDS, the total population consisted of 2330 participants (53.8\% females, mean age 14.7 (SD 1.2) years) or 1804 participants ( $52.6 \%$ females, mean age 14.7 (SD 1.2) years) when excluding under-reporters. For all adapted
KIDMED scores, the total population involved 1114 participants (56.5\% females, mean age 14.8 (SD 1.3) years).

\section{Comparison of the different indices with food intakes}

Multilevel regression analysis of the zMDS_A and KIDMED_A with the usual consumption of different foods is shown in Tables 2 and 3, respectively. A significant positive association was found between water $(\mathrm{g} / \mathrm{d})$ and both indices $(\beta=0.0008$ and $\beta=0.0006$, respectively; both $P<0.0001)$. In contrast, soft drinks (g/d) showed a significant negative relationship with zMDS_A (Table 2), KIDMED_A (Table 3) and MDS_A (Supplemental Table S1.4; $\beta=-0.0011, \quad \beta=-0.0009$ and $\beta=-0.0004$, respectively; all $P<0.0001)$. Alcoholic beverages $(\mathrm{g} / \mathrm{d})$ and meat $(\mathrm{g} / \mathrm{d})$ presented a significant negative association ( $\beta=-0.0079$ and $\beta=-0.0095$; both $P<0.0001$, respectively) with zMDS_A. All non-recommended foods (all g/d) also presented a significant negative association 
Table 3 Association between the adapted KIDMED for adolescents (KIDMED_A) and food intakes among adolescents aged 12.5-17.5 years from nine European countries, Healthy Lifestyle in Europe by Nutrition in Adolescence (HELENA) study

\begin{tabular}{|c|c|c|c|}
\hline & \multicolumn{3}{|c|}{ KIDMED_A $(n$ 1114) } \\
\hline & $\beta$ & $95 \% \mathrm{Cl}$ & $P$ value \\
\hline \multicolumn{4}{|l|}{ Beverages } \\
\hline Water (g/d) & 0.0006 & $0.0004,0.0009$ & $<0.0001$ \\
\hline Coffee and tea $(\mathrm{g} / \mathrm{d})$ & 0.0024 & $0.0013,0.0035$ & $<0.0001$ \\
\hline Soups/bouillon (g/d) & -0.0009 & $-0.0032,0.0013$ & 0.419 \\
\hline \multicolumn{4}{|l|}{ Bread \& Cereals } \\
\hline Bread and rolls $(\mathrm{g} / \mathrm{d})$ & 0.0095 & $0.0071,0.0119$ & $<0.0001$ \\
\hline Breakfast cereals $(\mathrm{g} / \mathrm{d})$ & 0.0270 & $0.0210,0.0329$ & $<0.0001$ \\
\hline \multicolumn{4}{|l|}{ Potatoes \& Grains } \\
\hline Rice and other grains (g/d) & 0.0024 & $-0.0009,0.0058$ & 0.154 \\
\hline Starch roots, potatoes (g/d) & 0.0018 & $-0.0012,0.0048$ & 0.244 \\
\hline Pasta $(\mathrm{g} / \mathrm{d})$ & 0.0026 & $0.0001,0.0051$ & 0.035 \\
\hline Vegetables $(g / d)$ & 0.0108 & $0.0086,0.0126$ & $<0.0001$ \\
\hline Fruits $(g / d)$ & 0.0077 & $0.0065,0.0089$ & $<0.0001$ \\
\hline \multicolumn{4}{|l|}{ Milk Products } \\
\hline Milk, yoghurt and milk beverages (g/d) & 0.00137 & $-0.00004,0.00280$ & 0.058 \\
\hline Desserts and puddings, milk based (g/d) & -0.0032 & $-0.0081,0.0017$ & 0.200 \\
\hline Cheese $(g / d)$ & 0.0288 & $0.0230,0.0346$ & $<0.0001$ \\
\hline \multicolumn{4}{|l|}{ Meat/Fish/Egg/Meat Alternatives } \\
\hline Meat $(g / d)$ & -0.0010 & $-0.0028,0.0007$ & $0 \cdot 271$ \\
\hline Fish products (g/d) & 0.0033 & $-0.0029,0.0095$ & 0.294 \\
\hline Eggs $(g / d)$ & 0.0131 & $0.0044,0.0217$ & 0.003 \\
\hline Meat substitutes, nuts and pulses (g/d) & 0.0110 & $0.0070,0.0150$ & $<0.0001$ \\
\hline \multicolumn{4}{|l|}{ Fats \& Oils } \\
\hline Margarine and vegetable oils ( $\mathrm{g} / \mathrm{d})$ & 0.0135 & $0.0005,0.0265$ & 0.041 \\
\hline Butter and animal fats (g/d) & 0.0217 & $0.0116,0.0319$ & $<0.0001$ \\
\hline \multicolumn{4}{|l|}{ Non-recommended foods } \\
\hline \multicolumn{4}{|l|}{ Snacks \& Candy } \\
\hline Cakes, pies, biscuits (g/d) & -0.0042 & $-0.0074,-0.0010$ & 0.010 \\
\hline Savoury snacks $(g / d)$ & -0.0064 & $-0.01489,0.0019$ & $0 \cdot 132$ \\
\hline Sugar, honey, jam, candies, chocolate (g/d) & 0.0104 & $0.0038,0.0170$ & 0.002 \\
\hline Sauces \& Creams $(\mathrm{g} / \mathrm{d})$ & 0.0015 & $-0.0034,0.0065$ & 0.538 \\
\hline \multicolumn{4}{|l|}{ Drinks } \\
\hline Carbonated/soft/isotonic drinks (g/d) & -0.0009 & $-0.0013,-0.0005$ & $<0.0001$ \\
\hline Fruit and vegetable juices $(\mathrm{g} / \mathrm{d})$ & 0.0009 & $0.0001,0.0017$ & 0.019 \\
\hline Alcoholic beverages $(\mathrm{g} / \mathrm{d})$ & -0.0002 & $-0.0015,0.0009$ & 0.657 \\
\hline
\end{tabular}

KIDMED, Mediterranean Diet Quality Index for children and adolescents; $\beta$, standardized regression coefficient.

Multilevel regression analyses with inclusion of a random intercept for centre and corrected for age and sex as independent variables. Bonferroni correction resulted in level of significance $<0.0019$

with zEnMDS_A (Supplemental Table S1.8). Sugar/honey/ $\mathrm{jam} / \mathrm{candies} / \mathrm{chocolate}$ (all g/d) showed a negative tendency association $(\beta=-0.0076, P=0.057)$. A significant positive link $(P<0.0001)$ was observed for rice, bread and cereals, pasta, fat and oil, vegetables, fruits and fish with zMDS_A and KIDMED_A (except fish; all g/d). Potatoes $(\mathrm{g} / \mathrm{d})$ showed a significant positive association with zMDS_A. zEnMDS_A presented positive and significant relationship with healthy foods such as fish, fruit, vegetables, meat, nuts and pulses (all g/d), among others (see Supplemental Table S1.8).

\section{Comparison of the different indices with nutrient intakes}

Tables 4 and 5 show the results of macronutrients for zMDS_A and KIDMED_A, respectively. For zMDS_A, a positive association (all $P<0.0001$, except for cholesterol (mg/d), $P=0.005)$ was observed with all macro- and micronutrients (Table 4). The usual intake of macronutrients, minerals and vitamins was positively related to the KIDMED_A (all $P<0.0001$, except for monosaccharides $(\mathrm{mg} / \mathrm{d}), P=0.002 ;$ PUFA (mg/d), $P=0.038$; and cholesterol $(\mathrm{mg} / \mathrm{d}), P=0.002$; Table 5). However, zEnMDS_A presented negative associations with the majority of macroand micronutrients, vitamins and minerals (Supplemental Table S2.8).

\section{Comparison of the different indices with nutritional biomarker levels}

Tables 6 and 7 describe the results between the zMDS_A and KIDMED_A, respectively, and nutritional biomarkers in subgroups of 697 participants (under-reporters included) and 552 adolescents excluding under-reporters. A significant positive association (all $P<0.01$ ) was observed between zMDS_A and KIDMED_A and vitamin D (nmol/l), vitamin C (mg/dl), plasma folate $(\mathrm{nmol} / \mathrm{l})$, holo-transcobalamin ( $\mathrm{pmol} / \mathrm{l}), \beta$-carotene $(\mathrm{ng} / \mathrm{ml})$ and $n$-3 fatty acids $(\mathrm{ng} / \mathrm{ml})$. Trans-fatty acids $(\mu \mathrm{mol} / \mathrm{l})$ showed 
Table 4 Association between the adapted Mediterranean Diet Score for Adolescents by Z-score method (zMDS_A) and usual intake of macro- and micronutrients among adolescents aged 12.5-17.5 years from nine European countries, Healthy Lifestyle in Europe by Nutrition in Adolescence (HELENA) study

\begin{tabular}{|c|c|c|c|}
\hline & \multicolumn{3}{|c|}{ zMDS_A ( $n$ 2330, under-reporters included) } \\
\hline & $\beta$ & $95 \% \mathrm{Cl}$ & $P$ value \\
\hline \multicolumn{4}{|l|}{ Macronutrients } \\
\hline Energy (kcal/d) & 0.0011 & $0.0009,0.0013$ & $<0.0001$ \\
\hline Protein (g/d) & 0.0222 & $0.0178,0.0265$ & $<0.0001$ \\
\hline Carbohydrates (g/d) & 0.0105 & $0.0092,0.0118$ & $<0.0001$ \\
\hline Total fat $(\mathrm{g} / \mathrm{d})$ & 0.000017 & $0.000013,0.00002$ & $<0.0001$ \\
\hline Water $(\mathrm{g} / \mathrm{d})$ & 0.0016 & $0.0014,0.0018$ & $<0.0001$ \\
\hline Fibre $(\mathrm{g} / \mathrm{d})$ & 0.2430 & $0.2274,0.2586$ & $<0.0001$ \\
\hline \multicolumn{4}{|l|}{ Carbohydrates } \\
\hline Monosaccharides (g/d) & 0.000016 & $0.000011,0.000020$ & $<0.0001$ \\
\hline Disaccharides $(\mathrm{g} / \mathrm{d})$ & 0.000013 & $0.000010,0.000016$ & $<0.0001$ \\
\hline Polysaccharides (g/d) & 0.000022 & $0.000016,0.000024$ & $<0.0001$ \\
\hline \multicolumn{4}{|l|}{ Fats } \\
\hline SFA $(m g / d)$ & 0.000023 & $0.000014,0.000032$ & $<0.0001$ \\
\hline MUFA (mg/d) & 0.000060 & $0.000049,0.000071$ & $<0.0001$ \\
\hline PUFA (mg/d) & 0.000096 & $0.000073,0.000120$ & $<0.0001$ \\
\hline Cholesterol (mg/d) & 0.0014 & $0.0004,0.0024$ & 0.005 \\
\hline \multicolumn{4}{|l|}{ Minerals } \\
\hline $\mathrm{Na}(\mathrm{mg} / \mathrm{d})^{*}$ & $5 \cdot 447$ & $4 \cdot 607,6 \cdot 286$ & $<0.0001$ \\
\hline $\mathrm{K}(\mathrm{mg} / \mathrm{d})$ & 0.0014 & $0.0013,0.0016$ & $<0.0001$ \\
\hline $\mathrm{Cl}(\mathrm{mg} / \mathrm{d})$ & 0.0006 & $0.0005,0.0007$ & $<0.0001$ \\
\hline $\mathrm{Ca}(\mathrm{mg} / \mathrm{d})$ & 0.0029 & $0.0025,0.0032$ & $<0.0001$ \\
\hline$M g(m g / d)$ & 0.0121 & $0.0110,0.0133$ & $<0.0001$ \\
\hline $\mathrm{Fe}(\mu \mathrm{g} / \mathrm{d})$ & 0.00019 & $0.00017,0.00022$ & $<0.0001$ \\
\hline $\mathrm{Cu}(\mu \mathrm{g} / \mathrm{d})$ & 0.0013 & $0.0012,0.0015$ & $<0.0001$ \\
\hline $\mathrm{Zn}(\mu \mathrm{g} / \mathrm{d})$ & 0.00020 & $0.00017,0.00024$ & $<0.0001$ \\
\hline$F(\mu \mathrm{g} / \mathrm{d})$ & 0.0029 & $0.0024,0.0034$ & $<0.0001$ \\
\hline lodine $(\mu \mathrm{g} / \mathrm{d})$ & 0.0388 & $0.0355,0.0420$ & $<0.0001$ \\
\hline $\mathrm{P}(\mathrm{mg} / \mathrm{d})$ & 0.0025 & $0.0022,0.0028$ & $<0.0001$ \\
\hline $\operatorname{Mn}(\mu \mathrm{g} / \mathrm{d})$ & 0.00071 & $0.00064,0.00079$ & $<0.0001$ \\
\hline \multicolumn{4}{|l|}{ Vitamins } \\
\hline Thiamin $(\mu \mathrm{g} / \mathrm{d})$ & 0.0017 & $0.0014,0.0020$ & $<0.0001$ \\
\hline Riboflavin ( $\mu \mathrm{g} / \mathrm{d})$ & 0.0018 & $0.0016,0.0020$ & $<0.0001$ \\
\hline Niacin $(\mu \mathrm{g} / \mathrm{d})$ & 0.00005 & $0.00002,0.00007$ & $<0.0001$ \\
\hline Pantothenic acid $(\mu \mathrm{g} / \mathrm{d})$ & 0.0006 & $0.0005,0.0007$ & $<0.0001$ \\
\hline Pyridoxine $(\mu \mathrm{g} / \mathrm{d})$ & 0.0016 & $0.0014,0.0018$ & $<0.0001$ \\
\hline Biotin $(\mu \mathrm{g} / \mathrm{d})$ & 0.0884 & $0.0805,0.0964$ & $<0.0001$ \\
\hline Total folic acid $(\mu \mathrm{g} / \mathrm{d})$ & 0.0225 & $0.0210,0.0240$ & $<0.0001$ \\
\hline Cobalamin $(\mu \mathrm{g} / \mathrm{d})$ & 0.1666 & $0.1139,0.2193$ & $<0.0001$ \\
\hline Vitamin $C(\mathrm{~g} / \mathrm{d})$ & 0.000020 & $0.000018,0.000022$ & $<0.0001$ \\
\hline Retinol equivalents $(\mu \mathrm{g} / \mathrm{d})$ & 0.0012 & $0.0009,0.0014$ & $<0.0001$ \\
\hline Vitamin $D(\mu \mathrm{g} / \mathrm{d})$ & 0.8781 & $0.7504,1.0058$ & $<0.0001$ \\
\hline Vitamin $E(\mu \mathrm{g} / \mathrm{d})$ & 0.00034 & $0.00031,0.00037$ & $<0.0001$ \\
\hline Vitamin K $(\mu \mathrm{g} / \mathrm{d})$ & 0.0128 & $0.0116,0.0141$ & $<0.0001$ \\
\hline
\end{tabular}

a significant negative association with zMDS_A, and KIDMED_A $(\beta=-0.3943$ and $\beta=-0.3855$, respectively; both $P<0 \cdot 05)$. In addition, total homocysteine ( $\mu \mathrm{mol} / \mathrm{l})$ showed a significant negative association with KIDMED_A $(\beta=-0 \cdot 1073, P=0 \cdot 002)$.

\section{Discussion}

Adherence to the Mediterranean diet has been quantified in diet quality indices that attempt to obtain a global evaluation of the quality of the diet based on a traditional reference pattern. However, this traditional reference pattern originally based upon adult populations has been adapted for use in children and adolescents, a population group with specific nutritional requirements when considering their growth needs. Therefore, different variants of the original MDS have been developed for use in child and adolescent populations, all considering different arguments for the inclusion of components such as alcohol and dairy products in the calculation of the MDS.

The results from the present cross-sectional study have shown that ZMDS_A and KIDMED_A followed by MDS_A were significantly associated with most nutritional biomarkers in the theorized directions. Moreover, our data seem to indicate that similar results were obtained 
Table 5 Association between the adapted KIDMED for adolescents (KIDMED_A) and usual intake of macro- and micronutrients among adolescents aged 12.5-17.5 years from nine European countries, Healthy Lifestyle in Europe by Nutrition in Adolescence (HELENA) study

\begin{tabular}{|c|c|c|c|}
\hline & \multicolumn{3}{|c|}{ KIDMED_A $(n$ 1114) } \\
\hline & $\beta$ & $95 \% \mathrm{Cl}$ & $P$ value \\
\hline \multicolumn{4}{|l|}{ Macronutrients } \\
\hline Energy (kcal/d) & 0.0005 & $0.0004,0.0007$ & $<0.0001$ \\
\hline Protein $(\mathrm{g} / \mathrm{d})$ & 0.0137 & $0.0095,0.0178$ & $<0.0001$ \\
\hline Carbohydrates (g/d) & 0.0045 & $0.0032,0.0057$ & $<0.0001$ \\
\hline Total fat $(\mathrm{g} / \mathrm{d})$ & 0.000010 & $0.000006,0.000014$ & $<0.0001$ \\
\hline Water $(\mathrm{g} / \mathrm{d})$ & 0.0010 & $0.0008,0.0012$ & $<0.0001$ \\
\hline Fibre $(\mathrm{g} / \mathrm{d})$ & 0.1040 & $0.0887,0.1193$ & $<0.0001$ \\
\hline \multicolumn{4}{|l|}{ Carbohydrates } \\
\hline Monosaccharides (g/d) & 0.000006 & $0.000002,0.000010$ & 0.002 \\
\hline Disaccharides $(\mathrm{g} / \mathrm{d})$ & 0.000007 & $0.000004,0.000010$ & $<0.0001$ \\
\hline Polysaccharides (g/d) & 0.000007 & $0.000007,0.000012$ & $<0.0001$ \\
\hline \multicolumn{4}{|l|}{ Fats } \\
\hline SFA $(m g / d)$ & 0.00002 & $0.00001,0.00003$ & $<0.0001$ \\
\hline MUFA (mg/d) & 0.00002 & $0.00001,0.00003$ & $<0.0001$ \\
\hline PUFA (mg/d) & 0.00002 & $0.00001,0.00004$ & 0.038 \\
\hline Cholesterol (mg/d) & 0.0015 & $0.0005,0.0025$ & 0.002 \\
\hline \multicolumn{4}{|l|}{ Minerals } \\
\hline $\mathrm{Na}(\mathrm{mg} / \mathrm{d})^{\star}$ & 3.4618 & $2 \cdot 6534,4 \cdot 2702$ & $<0.0001$ \\
\hline $\mathrm{K}(\mathrm{mg} / \mathrm{d})$ & 0.0007 & $0.0005,0.0008$ & $<0.0001$ \\
\hline $\mathrm{Cl}(\mathrm{mg} / \mathrm{d})$ & 0.0004 & $0.0003,0.0005$ & $<0.0001$ \\
\hline $\mathrm{Ca}(\mathrm{mg} / \mathrm{d})$ & 0.0017 & $0.0014,0.0020$ & $<0.0001$ \\
\hline $\mathrm{Mg}(\mathrm{mg} / \mathrm{d})$ & 0.0058 & $0.0047,0.0069$ & $<0.0001$ \\
\hline $\mathrm{Fe}(\mu \mathrm{g} / \mathrm{d})$ & 0.00004 & $0.00009,0.00012$ & $<0.0001$ \\
\hline $\mathrm{Cu}(\mu \mathrm{g} / \mathrm{d})$ & 0.0008 & $0.0006,0.0009$ & $<0.0001$ \\
\hline $\mathrm{Zn}(\mu \mathrm{g} / \mathrm{d})$ & 0.00016 & $0.00012,0.00019$ & $<0.0001$ \\
\hline$F(\mu \mathrm{g} / \mathrm{d})$ & 0.0020 & $0.0015,0.0025$ & $<0.0001$ \\
\hline lodine $(\mu \mathrm{g} / \mathrm{d})$ & 0.0209 & $0.0174,0.0244$ & $<0.0001$ \\
\hline$P(m g / d)$ & 0.0014 & $0.0012,0.0017$ & $<0.0001$ \\
\hline$M n(\mu \mathrm{g} / \mathrm{d})$ & 0.0003 & $0.0002,0.0004$ & $<0.0001$ \\
\hline \multicolumn{4}{|l|}{ Vitamins } \\
\hline Thiamin $(\mu \mathrm{g} / \mathrm{d})$ & 0.0009 & $0.0007,0.0012$ & $<0.0001$ \\
\hline Riboflavin $(\mu \mathrm{g} / \mathrm{d})$ & 0.0011 & $0.0009,0.0013$ & $<0.0001$ \\
\hline Niacin $(\mu \mathrm{g} / \mathrm{d})$ & 0.00004 & $0.00002,0.00007$ & $<0.0001$ \\
\hline Pantothenic acid $(\mu \mathrm{g} / \mathrm{d})$ & 0.00039 & $0.00032,0.0004$ & $<0.0001$ \\
\hline Pyridoxine $(\mu \mathrm{g} / \mathrm{d})$ & 0.0009 & $0.0006,0.0011$ & $<0.0001$ \\
\hline Biotin $(\mu \mathrm{g} / \mathrm{d})$ & 0.0388 & $0.0314,0.0463$ & $<0.0001$ \\
\hline Total folic acid $(\mu \mathrm{g} / \mathrm{d})$ & 0.0095 & $0.0080,0.0111$ & $<0.0001$ \\
\hline Cobalamin $(\mu \mathrm{g} / \mathrm{d})$ & 0.1188 & $0.0703,0.1674$ & $<0.0001$ \\
\hline Vitamin C $(\mathrm{g} / \mathrm{d})$ & 0.000010 & $0.000008,0.000012$ & $<0.0001$ \\
\hline Retinol equivalents $(\mu \mathrm{g} / \mathrm{d})$ & 0.0005 & $0.0004,0.0007$ & $<0.0001$ \\
\hline Vitamin D $(\mu \mathrm{g} / \mathrm{d})$ & 0.3170 & $0.1866,0.4474$ & $<0.0001$ \\
\hline Vitamin E $(\mu \mathrm{g} / \mathrm{d})$ & 0.00012 & $0.00009,0.00015$ & $<0.0001$ \\
\hline Vitamin K $(\mu \mathrm{g} / \mathrm{d})$ & 0.0067 & $0.0054,0.0081$ & $<0.0001$ \\
\hline
\end{tabular}

independently of the inclusion or exclusion of underreporters (results considering under-reporters are shown in the online supplementary material, Supplemental Annexes 1, 2 and 3).

Nutrient-dense food items, such as fish, fruits and vegetables, were positively associated with zMDS_A and KIDMED_A, whereas most of the energy-dense and nonrecommended foods (e.g. cakes, biscuits, soft drinks) showed negative associations.

At the level of food intake, Vyncke et al. ${ }^{(5)}$ investigated similar associations in relation to the Diet Quality Index for Adolescents (DQI-A); nevertheless, they did not find a significant relationship between the DQI-A and meat and fish intake. In our study, a negative and positive significant association was obtained between meat and fish intake, respectively, for KIDMED_A and zMDS_A, which was also found by Grosso et al. ${ }^{(42)}$. Moreover, a significant positive association was shown between MDS_A, zMDS_A and KIDMED_A and the consumption of fats and oils. A moderate intake of fat and oil is recommended because they are also important sources of essential fatty acids and vitamins. Furthermore, adolescents have higher fat intake needs, which is essential for growth ${ }^{(43)}$. However, high-fat diets may decrease insulin sensitivity and are positively associated with increased cardiovascular risk ${ }^{(44,45)}$, although a precise dose-response relationship has not been defined.

The preservation of an adequate hydration status in adolescents has been recognized as important, being related to 
Table 6 Association between the adapted Mediterranean Diet Score for Adolescents by Z-score method (zMDS_A) and nutritional biomarkers among adolescents aged 12.5-17.5 years from nine European countries, Healthy Lifestyle in Europe by Nutrition in Adolescence (HELENA) study

\begin{tabular}{lccc}
\hline & \multicolumn{2}{c}{ zMDS_A $(n 697$, under-reporters included $)$} \\
\cline { 2 - 4 } & $\beta$ & $95 \% \mathrm{Cl}$ & $P$ value \\
\hline Vitamin D (nmol/l) & 0.0163 & $0.0057,0.0268$ & 0.003 \\
Vitamin C $(\mathrm{mg} / \mathrm{dl})$ & 0.1109 & $0.0342,0.1877$ & 0.005 \\
Plasma folate $(\mathrm{nmol} / \mathrm{l})$ & 0.0432 & $0.0183,0.0680$ & 0.001 \\
Holo-transcobalamin $(\mathrm{TC}-\mathrm{Il} / \mathrm{B} 12)(\mathrm{pmol} / \mathrm{l})^{*}$ & 1.4924 & $0.1701,2.8147$ & 0.027 \\
Total homocysteine $(\mu \mathrm{mol} / \mathrm{l})$ & -0.0446 & $-0.1081,-0.0189$ & 0.168 \\
$\beta$-Carotene $(\mathrm{ng} / \mathrm{ml})$ & 0.0021 & $0.0007,0.0035$ & 0.003 \\
Retinol $(\mathrm{ng} / \mathrm{ml})$ & 0.0010 & $-0.0014,0.0036$ & 0.400 \\
TAG $(\mathrm{mg} / \mathrm{dl})$ & 0.0045 & $-0.0024,0.0116$ & 0.202 \\
$n$-3 Fatty acids $(\mu \mathrm{mol} / \mathrm{l})$ & 0.0075 & $0.0023,0.0127$ & 0.004 \\
Trans-fatty acids $(\mu \mathrm{mol} / \mathrm{l})$ & -0.3943 & $-0.7066,-0.0820$ & 0.013 \\
\hline
\end{tabular}

$\beta$, standardized regression coefficient.

Multilevel regression analyses with inclusion of a random intercept for centre and corrected for age and sex as independent variables. Bonferroni correction resulted in level of significance $<0.005$

*Variable was log-transformed to obtain a normal distribution.

Table 7 Association between the adapted KIDMED for adolescents (KIDMED A) and nutritional biomarkers among adolescents aged 12.5-17.5 years from nine European countries, Healthy Lifestyle in Europe by Nutrition in Adolescence (HELENA) study

\begin{tabular}{lccc}
\hline & \multicolumn{3}{c}{ KIDMED_A $(N$ 552) } \\
\cline { 2 - 4 } & \multicolumn{1}{c}{$\beta$} & $95 \% \mathrm{Cl}$ & $P$ value \\
\hline Vitamin D $(\mathrm{nmol} / \mathrm{l})$ & 0.0137 & $0.0043,0.0231$ & 0.004 \\
Vitamin C $(\mathrm{mg} / \mathrm{dl})$ & 0.1065 & $0.0350,0.1780$ & 0.004 \\
Plasma folate $(\mathrm{nmol} / \mathrm{l})$ & 0.0349 & $0.0113,0.0586$ & 0.004 \\
Holo-transcobalamin $(\mathrm{TC}-\mathrm{Il} / \mathrm{B} 12)(\mathrm{pmol} / \mathrm{l})^{*}$ & 1.7400 & $0.5234,2.956$ & 0.005 \\
Total homocysteine $(\mu \mathrm{mol} / \mathrm{l})$ & -0.1073 & $-0.1764,-0.0381$ & 0.002 \\
$\beta$-Carotene $(\mathrm{ng} / \mathrm{ml})$ & 0.0021 & $0.0007,0.0034$ & 0.002 \\
Retinol $(\mathrm{ng} / \mathrm{ml})$ & 0.0005 & $-0.0018,0.0029$ & 0.654 \\
TAG $(\mathrm{mg} / \mathrm{dl})$ & 0.0008 & $-0.0050,0.0067$ & 0.774 \\
$n$-3 Fatty acids $(\mu \mathrm{mol} / \mathrm{l})$ & 0.0065 & $0.0015,0.0116$ & 0.010 \\
Trans-fatty acids $(\mu \mathrm{mol} / \mathrm{l})$ & -0.3855 & $-0.7007,-0.0703$ & 0.017 \\
\hline
\end{tabular}

KIDMED, Mediterranean Diet Quality Index for children and adolescents; $\beta$, standardized regression coefficients.

Multilevel regression analyses with inclusion of a random intercept for centre and corrected for age and sex as independent variables. Bonferroni correction resulted in level of significance $<0.005$.

*Variable was log-transformed to obtain a normal distribution.

the ability to regulate body temperature and cognitive performance ${ }^{(46)}$. Water showed a positive association with all indices calculated $(P<0 \cdot 0001)$. Carbonated drinks presented a negative relationship with ZMDS_A and KIDMED_A, whereas there was a positive association between both indices and fruit and vegetables juices. No significant relationship between the MDS_A and zMDS_A and the usual intake of coffee was found. One reason for this could be a lower consumption of coffee and alcoholic beverages by the adolescent population included in the HELENA study ${ }^{(47)}$.

Another interesting finding was the positive association of MDS_A, zMDS_A and KIDMED_A with energy intake, in contrast with the negative association found by Vyncke et al. ${ }^{(43)}$ when investigating the association between energy intake and the DQI_A. Complex carbohydrates were positively associated with all indices except the zEnMDS_A. An important advantage of this energy-adjusted zEnMDS_A index is that it was negatively associated with energy intake. Vyncke et al. ${ }^{(5)}$ found a negative relationship between energy intake and the DQI-A. Our findings also indicate that there are positive associations between these indices and the usual intake of macro- and micronutrients. Furthermore, a positive and significant association was found for the zMDS_A, KIDMED_A and MDS_A with all minerals and vitamins. Our results are in concordance with Serra-Majem et al. ${ }^{(48)}$ except for vitamin E. Vyncke et al. ${ }^{(5)}$ did not find an association between vitamin $\mathrm{C}$ or carotene and the DQI-A. This would be considered an important point because the adequate intakes of vitamins and minerals are essential during childhood and adolescence ${ }^{(49,50)}$.

Nutritional biomarkers may offer advantages and be able to improve the estimates of dietary intake assessment due to the independence of their random errors in relation to the errors inherent to intake questionnaires ${ }^{(51)}$. Biomarkers have been recognized as potential tools for describing dietary patterns, since they may provide dietary information that is complementary to self-reported dietary 
intake $^{(52,53)}$. Not all nutrients have well-defined biological markers, and many are influenced by other factors than intake $^{(5)}$. In the present study, positive and strong associations were found between KIDMED_A and zMDS_A and levels of plasma folate and holo-transcobalamin in the expected direction. In addition, a significant negative association was shown between KIDMED_A and total homocysteine. Adequate folate and vitamin $\mathrm{B}_{12}$ levels are necessary for healthy growth and development, and deficiency at young ages is related to developmental delay, feeding problems, failure to thrive, anaemia and even irreversible neurological damage ${ }^{(54)}$. A deficiency of these vitamins usually leads to an increase in total homocysteine concentrations, which is considered an additional a marker for the status of folate and vitamin $\mathrm{B}_{12}{ }^{(55)}$. However, there are few studies analysing the association between these nutritional biomarkers and diet quality indices in adolescents; and therefore KIDMED_A has shown a good validity by confirming the expected association.

Among others, a significant and positive relationship was found between vitamin D and KIDMED_A and zMDS_A. This finding was important since vitamin $\mathrm{D}$ is involved in the immune system, bone mineralization and muscle tissue. This vitamin has been related with different pathologies such as cancer, diabetes, hyperactivity, hypertension and multiple sclerosis ${ }^{(49,56-59)}$. KIDMED_A and zMDS_A also showed a significant positive relationship with vitamin C. Likewise, other authors observed these relationships between different diet quality indices and nutritional biomarkers in people aged over 18 years. For example, Weinstein et $a l^{(60)}$ found a correlation between the Healthy Eating Index and serum vitamin $C$, serum folate and serum vitamin $B_{12}$ in a large population. Bach-Faig et $a l .{ }^{(52)}$ observed associations between high adherence to Mediterranean diet and high levels of $\beta$-carotene, vitamin $\mathrm{C}$ and folate. Okuda et al. ${ }^{(61)}$ found correlations between energy intake and $\beta$-carotene $(P<0.030)$. In our study, there was no association between zMDS_A and KIDMED_A and retinol. The absence of an association with retinol level might be attributed to the fact that this vitamin is prevalent in meat, and a significant negative relationship was found with zMDS_A and KIDMED_A for meat intake.

Regarding fatty acids, serum levels of trans-fatty acids showed an inverse relationship with the KIDMED_A and zMDS_A. This finding was also discovered by Vyncke et $a l .{ }^{(5)}$ with the DQI-A. This is an interesting result because higher levels of trans-fatty acids are related to an increase of cardiovascular risk ${ }^{(62)}$.

The aim of the present study was to obtain a holistic measure for the overall diet quality of an individual, using the Mediterranean diet as a reference. All different indices have advantages and disadvantages and the main disadvantage of the MDS, in comparison with the DQI-A from Vyncke et $a l .{ }^{(5)}$, is that energy intake was positively associated with zMDS_A and KIDMED_A. This is mainly a disadvantage when thinking about obesity prevention among youth. However, zEnMDS_A could be considered when energy intake will be analysed due to the negative association with usual energy intake. In our study, statistically significant associations were found with biomarkers representing long-term and short- to medium-term dietary intakes except for TAG and retinol.

\section{Strengths and limitations}

There are few studies investigating the use and validity of these indices in a European adolescent population. The MDS_A and KIDMED_A in the present study were not based on nutrient intakes, avoiding the limitations that coincide with the use of food composition data (such as the use of various tables in different countries with different methods of analysis used, unavailability of food items, loss of dietary information from mixed dishes, etc.).

All indices were calculated based on two self-administered, computer-assisted, non-consecutive $24 \mathrm{~h}$ recalls, among others. Following recommendations of the European Food Consumption Survey method (EFCOSUM), 24 h dietary recalls were preferred as these are open-ended questionnaires from which detailed information can be obtained. Moreover, the European Food Safety Authority indicates in all publications on dietary misreporting among children and adolescents, that more research on validity of dietary methods is needed in this young population group, considering also the issue of misreporting ${ }^{(63)}$. For that reason, under-reporters have been taken accounted for in the present study.

One limitation of the used method is, however, that information of only two days was obtained. Although this allows inclusion of exceptional intakes at the individual level, this effect is neutralized by the large number of observations. The $24 \mathrm{~h}$ dietary recall method does not allow quantifying proportions of non-consumers for particular food items, especially for infrequently consumed foods. In order to decrease this influence, nutrient intakes were corrected for within-person variability by applying the Multiple Source Method. In this respect, the $24 \mathrm{~h}$ dietary recalls were performed through the computer-assisted HELENA-DIAT software to standardize the recall procedures as much as possible.

The same food composition table for conversion of food intake data to estimated nutrient intakes was used for all survey centres ${ }^{(25)}$. This identified differences in definitions, analytical methods, units and modes of expression, which were overcome. The fact that one single database of food composition was used could be a limitation due to the composition of some foods that may vary between countries and this might have reduced the correlation with some biomarkers. Another limitation may be that the FFQ has been validated only in a Belgian youth population and not in the HELENA study ${ }^{(29)}$.

The present study used data from the largest European study investigating the association of lifestyle factors (such as diet) with health outcomes (like obesity and health 
biomarkers) among European adolescents. Even though the sample size is reduced for some of the sub-analyses, as described in the 'Methods and materials' section, all the variables included in the present study were well framed for this sample size.

\section{Conclusion}

The zMDS_A and KIDMED_A showed associations with nutrient and food intakes, especially with nutritional biomarkers, in the hypothesized directions. Although other variants also showed good associations with the indicators under study, they were less significant compared with the zMDS_A and KIDMED_A. Altogether, based on these results, we recommend the use of the continuous MDS_A score using the $Z$-score method or the adapted KIDMED score for use in European adolescents when investigating adherence to the Mediterranean diet among adolescents.

\section{Acknowledgements}

Acknowledgements: Many thanks to Christel Bierschbach, Adelheid Schuch, Anke Berchtold, Petra Pickert, Andre Spinneker, Ulrike Albers and Anke Carstensen for their contribution to laboratory work. Financial support: The HELENA study was support by the European Community Sixth RTD Framework Programme (Contract FOOD-CT2005-007034). There was additional support from the Spanish Ministry of Education (AGL2007-29784-E/ALI), Axis-Shield Diagnostics Ltd (Oslo, Norway), Abbot Científica S.A. (Spain) and Cognis GmbH. R.A.-U. obtained a travel grant from the Consejo Social de la Universidad Politécnica de Madrid and the work reported in this paper was undertaken while she was hosted by the International Agency for Research on Cancer. R.A.-U. is also supported by Universidad Politécnica de Madrid with a predoctoral scholarship. The funders had no role in the design, analysis or writing of this article. The content of this article reflects only the authors' views and the European Community is not liable for any use that may be made of the information contained herein. Conflict of interest: None. Authorship: L.A.M. coordinated the project. L.A.M., M.G.-G. and M.K. designed and carried out the HELENA project. R.A.-U. and M.G.-C. carried out data analyses and drafted the manuscript. S.B.-S., M.G.-G. and I.H. provided critical input on the data analyses and on earlier versions of the manuscript. All authors contributed to interpretation of the data and reviewed the submitted manuscript. Ethics of human subject participation: The HELENA study was conducted following the ethical guidelines of the Declaration of Helsinki, the Good Clinical Practice rules, and the legislation about clinical research in human subjects in each of the participating countries. Written informed consent was obtained from all adolescents, their parents or guardians, and the protocol was approved by the Human Research
Review Committees of the centres involved. IARC disclaimer: Where authors are identified as personnel of the International Agency for Research on Cancer/World Health Organization, the authors alone are responsible for the views expressed in this article and they do not necessarily represent the decisions, policy or views of the International Agency for Research on Cancer/World Health Organization.

\section{Supplementary material}

To view supplementary material for this article, please visit https://doi.org/10.1017/S1368980019001022

Author ORCID. (1) Silvia Bel-Serrat, 0000-00033698-2619.

\section{References}

1. Iaccarino P, Scalfi L \& Valerio G (2017) Adherence to the Mediterranean diet in children and adolescents: a systematic review. Nutr Metab Cardiovasc Dis 27, 283-299.

2. Waters E, de Silva-Sanigorski A, Hall BJ et al. (2011) Interventions for preventing obesity in children. Cochrane Database Syst Rev issue 12, CD001871.

3. Garcia Cabrera S, Herrera Fernandez N, Rodriguez Hernandez C et al. (2015) KIDMED test; prevalence of low adherence to the Mediterranean diet in children and young; a systematic review. Nutr Hosp 32, 2390-2399.

4. Peng W, Berry EM \& Goldsmith R (2019) Adherence to the Mediterranean diet was positively associated with micronutrient adequacy and negatively associated with dietary energy density among adolescents. J Hum Nutr 32, 41-52.

5. Vyncke K, Cruz Fernandez E, Fajo-Pascual M et al. (2013) Validation of the Diet Quality Index for Adolescents by comparison with biomarkers, nutrient and food intakes: the HELENA study. Br J Nutr 109, 2067-2078.

6. Serra-Majem L, Ribas L, Ngo J et al. (2004) Food, youth and the Mediterranean diet in Spain. Development of KIDMED, Mediterranean Diet Quality Index in children and adolescents. Public Health Nutr 7, 931-935.

7. Feskanich D, Rockett HR \& Colditz GA (2004) Modifying the Healthy Eating Index to assess diet quality in children and adolescents. J Am Diet Assoc 104, 1375-1383.

8. Kranz S, Findeis JL \& Shrestha SS (2008) Use of the Revised Children's Diet Quality Index to assess preschooler's diet quality, its sociodemographic predictors, and its association with body weight status. J Pediatr (Rio J) 84, 26-34.

9. Manios Y, Kourlaba G, Grammatikaki E et al. (2010) Development of a diet-lifestyle quality index for young children and its relation to obesity: the Preschoolers Diet-Lifestyle Index. Public Health Nutr 13, 2000-2009.

10. Manios Y, Kourlaba G, Grammatikaki E et al. (2010) Development of a lifestyle-diet quality index for primary schoolchildren and its relation to insulin resistance: the Healthy Lifestyle-Diet Index. Eur J Clin Nutr 64, 1399-1406.

11. Garcia-Marcos L, Canflanca IM, Garrido JB et al. (2007) Relationship of asthma and rhinoconjunctivitis with obesity, exercise and Mediterranean diet in Spanish schoolchildren. Thorax 62, 503-508.

12. Grosso G \& Galvano F (2016) Mediterranean diet adherence in children and adolescents in southern European countries. NFS J 3, 13-19.

13. Handeland K, Kjellevold M, Wik-Markhus M et al. (2016) A diet score assessing Norwegian adolescents' adherence to 
dietary recommendations - development and test-retest reproducibility of the score. Nutrients $\mathbf{2 9}, 8$.

14. Darnton-Hill I, Nishida C \& James WP (2004) A life course approach to diet, nutrition and the prevention of chronic diseases. Public Health Nutr 7, 101-121.

15. Castro-Quezada I, Roman-Vinas B \& Serra-Majem L (2014) The Mediterranean diet and nutritional adequacy: a review. Nutrients 3, 231-248.

16. Moreno LA, González-Gross M, Kersting M et al. (2008) Assessing, understanding and modifying nutritional status, eating habits and physical activity in European adolescents: the HELENA (Healthy Lifestyle in Europe by Nutrition in Adolescence) study. Public Health Nutr 11, 288-299.

17. Beghin L, Castera M, Manios Y et al. (2008) Quality assurance of ethical issues and regulatory aspects relating to good clinical practices in the HELENA Cross-Sectional Study. Int J Obes (Lond) 32, Suppl. 5, 12-18.

18. Black AE (2000) Critical evaluation of energy intake using the Goldberg cut-off for energy intake:basal metabolic rate. A practical guide to its calculation, use and limitations. Int J Obes Relat Metab Disord 24, 1119-1130.

19. Biró G, Hulshof KF, Ovesen L et al. (2002) Selection of methodology to assess food intake. Eur J Clin Nutr 56, Suppl. 2, S25-S32.

20. Gilbert C, Hegyi A, Sanchez MJ et al. (2008) Qualitative research exploring food choices and preferences of adolescents in Europe. HELENA Deliverable, 11. http://www. helenastudy.com/packages.php (accessed October 2018).

21. Gilbert CC, Hall G, Hegyi A et al. (2013) Food choices and preferences. In HELENA Cross-Sectional Study Manual of Operations, pp. 101-109 [ M Gonzalez-Gross, S De Henauw, FF Gottrand et al., editors]. Zaragoza: University of Zaragoza.

22. Vereecken CA, Covents M, Matthys C et al. (2005) Young adolescents' nutrition assessment on computer (YANA-C). Eur J Clin Nutr 59, 658-667.

23. Vereecken CA, Covents M, Sichert-Hellert W et al. (2008) Development and evaluation of a self-administered computerized 24-h dietary recall method for adolescents in Europe. Int J Obes (Lond) 32, Suppl. 5, 26-34.

24. Dehne LI, Klemm C, Henseler G et al. (1999) The German Food Code and Nutrient Data Base (BLS II.2). Eur J Epidemiol 15, 355-359.

25. Julian-Almarcegui C, Bel-Serrat S, Kersting M et al. (2016) Comparison of different approaches to calculate nutrient intakes based upon 24-h recall data derived from a multicenter study in European adolescents. Eur J Nutr 55, 537-545.

26. Haubrock J, Harttig U, Souverein O et al. (2010) An improved statistical tool for estimating usual intake distributions: the Multiple Source Method (MSM). Arch Public Health 68, Suppl. 1, S15-S16.

27. Haubrock J, Harttig U, Souverein O et. al. (2010) An improved statistical tool for estimating usual intake distributions: the Multiple Source Method (MSM). Arch Public Health 68, Suppl. 1, S15-S16; available at https://www.wiv-isp.be/ aph/pdf/APH68_S15-S16.pdf

28. Vereecken C, Dohogne S, Covents M et al. (2010) How accurate are adolescents in portion-size estimation using the computer tool Young Adolescents' Nutrition Assessment on Computer (YANA-C)? Br J Nutr 103, 1844-1850.

29. Vereecken CA \& Maes L (2003) A Belgian study on the reliability and relative validity of the Health Behaviour in School-Aged Children food-frequency questionnaire. Public Health Nutr 6, 581-588.

30. Trichopoulou A, Costacou T, Bamia C et al. (2003) Adherence to a Mediterranean diet and survival in a Greek population. $N$ Engl J Med 348, 2599-2608.

31. Gonzalez-Gross M, Breidenassel C, Gomez-Martinez $\mathrm{S}$ et al. (2008) Sampling and processing of fresh blood samples within a European multicenter nutritional study: evaluation of biomarker stability during transport and storage. Int $J$ Obes (Lond) 32, Suppl. 5, S66-S75.

32. Jacques PF, Sulsky SI, Sadowski JA et al. (1993) Comparison of micronutrient intake measured by a dietary questionnaire and biochemical indicators of micronutrient status. Am JClin Nutr 57, 182-189.

33. Bates CJ, Rutishauser IH, Black AE et al. (1979) Long-term vitamin status and dietary intake of healthy elderly subjects. 2. Vitamin C. Br J Nutr $\mathbf{4 2}, 43-56$.

34. Jenab M, Slimani N, Bictash M et al. (2009) Biomarkers in nutritional epidemiology: applications, needs and new horizons. Hum Genet 125, 507-525.

35. Willett WC, Stampfer MJ, Underwood BA et al. (1983) Vitamins A, E, and carotene: effects of supplementation on their plasma levels. Am J Clin Nutr 38, 559-566.

36. Rock CL, Swendseid ME, Jacob RA et al. (1992) Plasma carotenoid levels in human subjects fed a low carotenoid diet. $J$ Nutr 122, 96-100.

37. Andersen LF, Solvoll K \& Drevon CA (1996) Very-long-chain $n-3$ fatty acids as biomarkers for intake of fish and $n-3$ fatty acid concentrates. Am J Clin Nutr 64, 305-311.

38. Hodge AM, Simpson JA, Gibson RA et al. (2007) Plasma phospholipid fatty acid composition as a biomarker of habitual dietary fat intake in an ethnically diverse cohort. Nutr Metab Cardiovasc Dis 17, 415-426.

39. Hodson L, Skeaff CM \& Fielding BA (2008) Fatty acid composition of adipose tissue and blood in humans and its use as a biomarker of dietary intake. Prog Lipid Res 47, 348-380.

40. Baylin A, Kim MK, Donovan-Palmer A et al. (2005) Fasting whole blood as a biomarker of essential fatty acid intake in epidemiologic studies: comparison with adipose tissue and plasma. Am J Epidemiol 162, 373-381.

41. Sonnenberg LM, Quatromoni PA, Gagnon DR et al. (1996) Diet and plasma lipids in women. II. Macronutrients and plasma triglycerides, high-density lipoprotein, and the ratio of total to high-density lipoprotein cholesterol in women: the Framingham nutrition studies. J Clin Epidemiol 49, 665-672.

42. Grosso G, Marventano S, Buscemi S et al. (2013) Factors associated with adherence to the Mediterranean diet among adolescents living in Sicily, Southern Italy. Nutrients $\mathbf{4}$, 4908-4923.

43. Vyncke KE, Libuda L, De Vriendt T et al. (2012) Dietary fatty acid intake, its food sources and determinants in European adolescents: the HELENA (Healthy Lifestyle in Europe by Nutrition in Adolescence) Study. Br J Nutr 108, 2261-2673.

44. Appel LJ, Sacks FM, Carey VJ et al. (2005) Effects of protein, monounsaturated fat, and carbohydrate intake on blood pressure and serum lipids: results of the OmniHeart randomized trial. JAMA 16, 2455-2464.

45. Ruiz E, Avila JM, Valero T et al. (2015) Energy intake, profile, and dietary sources in the Spanish population: findings of the ANIBES study. Nutrients 12, 4739-4762.

46. Edmonds CJ \& Burford D (2009) Should children drink more water? the effects of drinking water on cognition in children. Appetite 52, 776-779.

47. Duffey KJ, Huybrechts I, Mouratidou T et al. (2012) Beverage consumption among European adolescents in the HELENA study. Eur J Clin Nutr 66, 244-252.

48. Serra-Majem L, Ribas L, Garcia A et al. (2003) Nutrient adequacy and Mediterranean diet in Spanish school children and adolescents. Eur J Clin Nutr 57, Suppl. 1, 35-39.

49. Gonzalez-Gross M, Valtuena J, Breidenassel C et al. (2012) Vitamin D status among adolescents in Europe: the Healthy Lifestyle in Europe by Nutrition in Adolescence study. BrJ Nutr 107, 755-764.

50. Amit M (2010) Vegetarian diets in children and adolescents. Paediatr Child Health 15, 303-314. 
51. Yokota RT, Miyazaki ES \& Ito MK (2010) Applying the triads method in the validation of dietary intake using biomarkers. Cad Saude Publica 26, 2027-2037.

52. Bach-Faig A, Geleva D, Carrasco J et al. (2006) Evaluating associations between Mediterranean diet adherence indexes and biomarkers of diet and disease. Public Health Nutr $\mathbf{9}$, 1110-1117.

53. Prentice RL, Sugar E, Wang CY et al. (2002) Research strategies and the use of nutrient biomarkers in studies of diet and chronic disease. Public Health Nutr 5, 977-984.

54. Selhub J \& Paul L (2011) Folic acid fortification: why not vitamin $\mathrm{B}_{12}$ also? Biofactors 37, 269-271.

55. Obeid R, Munz W, Jäger M et al. (2005) Biochemical indexes of the $\mathrm{B}$ vitamins in cord serum are predicted by maternal B vitamin status. Am J Clin Nutr 82, 133-139.

56. Bischoff-Ferrari HA (2011) Vitamin D: role in pregnancy and early childhood. Ann Nutr Metab 59, 17-21.

57. Zhang R \& Naughton DP (2010) Vitamin D in health and disease: current perspectives. Nutr J9, 65.

58. Holick MF (2007) Vitamin D deficiency. $N$ Engl J Med 19, 266-281.
59. Elmadfa I, Godina-Zarfl B, Dichtl M et al. (1994) The Austrian Study on Nutritional Status of 6- to 18-year-old pupils. Bibl Nutr Dieta 51, 62-67.

60. Weinstein SJ, Vogt TM \& Gerrior SA (2004) Healthy Eating Index scores are associated with blood nutrient concentrations in the third National Health and Nutrition Examination Survey. J Am Diet Assoc 104, 576-584.

61. Okuda M, Sasaki S, Bando N et al. (2009) Carotenoid, tocopherol, and fatty acid biomarkers and dietary intake estimated by using a brief self-administered diet history questionnaire for older Japanese children and adolescents. J Nutr Sci Vitaminol (Tokyo) 55, 231-241.

62. de Souza RJ, Mente A, Maroleanu A et al. (2015) Intake of saturated and trans unsaturated fatty acids and risk of all cause mortality, cardiovascular disease, and type 2 diabetes: systematic review and meta-analysis of observational studies. BMJ 351, h3978.

63. EFSA/EU Menu Guidance (2013) Example of a protocol for identification of misreporting (under- and overreporting of energy intake based on the PILOT-PANEU project. http:// www.efsa.europa.eu/sites/default/files/efsa_rep/blobserver_ assets/3944A-8-2-1.pdf (accessed June 2016). 